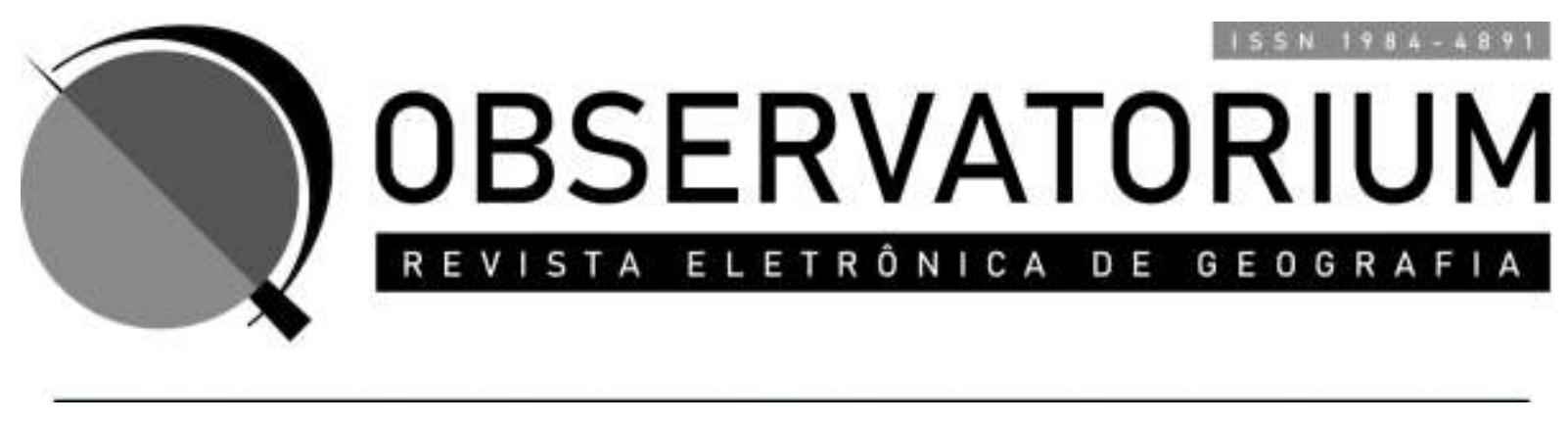

\title{
A CARTOGRAFIA ESCOLAR PARA COMPREENDER AS DINÂMICAS E ESPECIFICIDADES REGIONAIS NO ENSINO FUNDAMENTAL: QUESTÕES TEÓRICAS E PRÁTICAS
}

The usage of school cartography to understand the regional dynamics and specificities in elementary school: theoretical and practical issues.

\section{Pedro da Costa Alamy ${ }^{1}$ \\ Tulio Barbosa ${ }^{2}$}

\section{RESUMO}

O presente trabalho busca superar a linguagem técnica dos livros didáticos que apresentam mapas e elementos da ciência cartográfica no ensino de Geografia, pois não propõem os livros didáticos um trabalho que revele as condições vividas pelos sujeitos nas suas regiões com uma sistematização didática e pedagógica que consiga direcionar os estudantes para um caminho amplo de entendimento das relações do que seja a cartografia com suas especificidades e sua vivência naquela região com suas particularidades, ou seja, os trabalhos desenvolvidos com cartografia sinalizam a localização, duração e diferenciação, mas ignoram aspectos de vivência que também estão mapeadas e organizadas a partir de duração, intensidade e extensão, mas em outras linguagens e símbolos, com os quais os estudantes do ensino fundamental precisam dominar.

PALAVRAS-CHAVE: Educação, Região, Geografia, Ensino, Cartografia.

\begin{abstract}
The present work seeks to overcome the technical language of textbooks that presents maps and cartographic science elements in Geography teaching, as textbooks do not propose a view that reveals the subject's living experiences in their regions with

\footnotetext{
${ }^{1}$ Discente do curso de Graduação em Geografia do Instituto de Geografia (IG) da Universidade Federal de Uberlândia (UFU). Bolsista do PET MEC Geografia do IG-UFU. E-mail: pedro.alamay@ufu.br

2 Docente do Instituto de Geografia (IG) da Universidade Federal de Uberlândia (UFU) nos cursos de Graduação e Pós-Graduação em Geografia. Tutor do PET MEC Geografia do IG-UFU. E-mail: tuliobarbosa@ufu.br
} 
didactic and pedagogical systematization that can guide students towards a broad path of understanding the relationship between cartography and its specificities and its experience in that region with its particularities, that is, the cartography works show the location, duration and differentiation, but ignores aspects of experience that are also mapped and organized based on duration, intensity and extension, but in other languages and symbols, which elementary school students need to master.

KEYWORDS: Education, Region, Geography, Teaching, Cartography.

\section{INTRODUÇÃO}

Cartografia e Geografia partem da mesma categoria: o espaço. A Cartografia nutre sua ciência por meio de uma linguagem que constata as ocupações e as lacunas do espaço por meio de representações simbólicas informativas, comunicativas e reflexivas, todavia, somente é possível constituir as informações cartográficas e materializar suas questões nos mapas se tiver um banco de dados, de informações, de questões, de pesquisas, enfim, a Cartografia depende da ciência geográfica para auxiliar na promoção do conhecimento ao mesmo tempo a Geografia depende da Cartografia para sistematizar suas questões e respostas resultadas das pesquisas.

Deste modo, a Cartografia e a Geografia não podem constituir conhecimentos independentes, visto que a dependência objetivada nas perquirições fundamenta o aperfeiçoamento epistemológico, social, político, econômico, cultural e outros que se espacializam.

A Cartografia, depende de outras informações e conhecimentos oriundos das Ciências Humanas, mesmo tendo a Cartografia constituída por outros conhecimentos é a Geografia que mais trabalha com essa ciência do conhecimento mapeado. A relação entre Cartografia e Geografia tomam ainda mais volume na escola, ou seja, a educação geográfica obrigatória no Ensino Fundamental é consorciada com as exigências legais, institucionais e pedagógicas com os temas e problemas da Cartografia.

A educação escolar geográfica é composta por conhecimentos originários da História, das Ciências Sociais, da Estatística, da Filosofia e da Cartografia; assim, a educação geográfica na escola tem um grande cabedal de conhecimento para ser ensinado, todavia, é a Cartografia que mais sinaliza e demonstra as questões didática no processo de ensinoaprendizagem. 
A Cartografia, portanto, é fundamental para o ensino de Geografia e é ao mesmo tempo uma ciência que promove o conhecimento e também material formativo e didático.

O presente trabalho busca evidenciar algumas questões e respostas para compreender a dinâmica do ensino de Geografia pela Cartografia Escolar na compreensão de mapas temáticos das diferentes regiões brasileiras. Deste modo, o trabalho objetiva constituir um caminho metodológico de ensino para pensar a linguagem cartográfica e geográfica como mediação científica diante da realidade.

A Cartografia e a Geografia desse trabalho parte das questões próprias do materialismo histórico e dialético apoiadas na psicologia soviética de Vygotsky (1990 e 1998) para refletirmos a formação do conhecimento, deste modo, as questões formativas pedagógicas precisam coadunar com as questões geográficas para alcançarem a promoção do ensino de uma linguagem universal que possam interpretar ao mesmo tempo mapas e a própria realidade; assim, Escolar (1996), Rique da Silva (2004), Gomes (1995) e Santos (1987 e 2009) constituem a base epistemológica da Geografia para a formulação de práticas escolares cartográficas.

O diálogo do ensino com a Cartografia partirá de trabalhos que consorciam a partir da Geografia, assim, Joly (1990), Francischett (2014), Fonseca (2004) e Richter (2010). Bem como as questões de ensino partirão das exigências da BNCC, todavia, tais exigências serão discutidas a partir de uma reflexão crítica e promotora de conhecimentos voltados para a ampliação da ética, da democracia e dos direitos humanos.

\section{2- A LINGUAGEM UNIVERSAL DA CARTOGRAFIA PARA A GEOGRAFIA ESCOLAR PARA ALCANÇAR A REGIÃO}

A Geografia Escolar constitui um campo de conhecimento e de ensino voltado para as questões determinadas pelo Estado nas suas legislações e nas publicações institucionais; assim, não se pode ensinar Geografia sem passar pelas exigências legais e pelo sentido institucional.

O currículo escolar da Geografia no Ensino Fundamental parte da localização até alcançar as relações escalares e seus movimentos que são compreendidos espacialmente. A localização é significativa na Geografia e no $6^{\circ}$ ano e no $7^{\circ}$ ano do Ensino Fundamental, ela é importante para que alunas e alunos consigam compreender a promoção entre o local da existência e suas múltiplas variáveis, mas não podemos fixar o local como espaço meramente 
geométrico, como salientou Rique da Silva (2004), é preciso como afirmou a autora compreender essa localização como instância social.

Neste sentido, a linguagem cartográfica também precisa ser compreendida como instância social, isto é, os signos e os símbolos de informação, comunicação e conhecimento não podem ser trabalhados sem trazer a realidade imediata e próxima para alunas e alunos do Ensino Fundamental. Segundo Vygotsky (1990, p. 80): "Parece-nos óbvio que um conceito possa submeter-se à consciência e ao controle deliberado somente quando começa a fazer parte de um sistema”. Assim, a construção de uma linguagem cartográfica passa pela necessidade da expressão dada por uma sistematização de sentidos, valores e correspondências.

O sistema da linguagem cartográfica depende, apoiados em Vygostky (1990), será processado como conceito na escola e esses conceitos terão o apoio de outros para serem firmados como um sistema.

Ao elencarmos a preocupação da linguagem universal da Cartografia para a Geografia Escolar evidenciamos um problema de organização dos sentidos interpretativos dos símbolos cartográficos para que alunas e alunos consigam exercer o domínio teórico e processual das relações entre as diversas localizações geográficas e suas especificidades delimitadas como regiões.

Segundo Francischett (2014, p.844): "A metodologia para a leitura do mapa consiste em determinar o que é e para que é o uso do mapa”. Esse apontamento nos leva até Vygotsky (1990) para a delimitação do sentido conceitual dentro de um sistema; assim, um mapa tem objetivos específicos ao ser confeccionado e muitos outros para seu uso pela Geografia Escolar.

Os mapas sobre as diferentes regiões brasileiras indicam questões que serão apresentadas na escola por meio da mediação docente. Os mapas das regiões brasileiras, com os quais trabalhamos, são temáticos e com isso implicam na formulação de conceitos ao mesmo tempo em que esses conceitos retornam para a promoção de um sentido quanto a região. A região não pode ser compreendida como estática, já que a mesma como instância social é promotora de relações instituídas pelo mercado, pelo Estado, pelas particularidades biogeográficas, enfim, por dinamismo que a definem.

As dinâmicas regionais existem como forma de organização da especificidade de cada uma nos aspectos culturais, econômicos, ecológicos, enfim, em muitos aspectos que são significativos para o entendimento da espacialidade que se movimenta dentro de um limite determinado por um recorte. Esse recorte é que especifica um tema ou questão que dá 
destaque para o que categorizou na Geografia como região, ou seja, uma parte do espaço com especificidades e dinâmicas próprias é definida como região e com isso consegue delimitar questões, similitudes, diferenças, continuidades e descontinuidades.

Para Gomes (1995) a região como categoria da Geografia existe a partir de inúmeras disputas conceituais, assim, essa construção da região passa pelos objetivos de categorização do espaço dentro de uma lógica definidora de um sentido, por isso, entendemos que a região é uma construção política, jurídica, econômica, cultural e ambiental, tal classificação nutre a composição de um sentido para pensar o humano, as técnicas, a produção e a natureza numa dada área que tem muito mais funções do que apenas a delimitação.

A relação entre a Cartografia e a Região é importante por instrumentalizar diretamente com técnicas de interpretação, comparação, simulação, planejamento e intervenção na realidade, ou seja, ao aplicarmos o conhecimento Geográfico na leitura do mapa sinalizando as especificidades de suas dinâmicas fomentamos nos alunos e alunas do ensino fundamental a capacidade crítica na relação processual da imagem, de dados e símbolos.

Nossos esforços teóricos e práticos concentrarão no $6^{\circ}$ e $7^{0}$ ano do Ensino Fundamental como forma de compreender os mecanismos de construção de uma Geografia do Brasil inserida numa lógica regionalista; assim, evidenciaremos as regiões brasileiras com suas questões próprias para refletirmos as mesmas pela linguagem e interpretação cartográfica somadas aos objetivos da leitura dos mapas, com isso o papel docente mostrase extremamente significativo.

Deste modo, a categoria região compreende a especificidade do espaço nas suas dinâmicas que são exclusivas dentro de um enredo próprio que fundamenta a escala regional como diferença, limite e articulação de formações humanas e naturais; assim, por meio da categoria região promovemos pelo ensino de Cartografia apreender o espaço na escala regional nos diferentes graus e articulações desses com múltiplas variáveis e extensões na relação dialética entre sociedade e natureza.

A relação entre a legenda e o mapa passa a ter um sentido de promoção de questões que serão levantadas pela mediação docente articulada ao projeto pedagógico da escola, ao currículo escolar da mesma e as exigências legais. Todavia, a legenda não fornece todas as informações para a leitura de um mapa, pois o mapa poderá ser lido pelas questões e necessidades da sala de aula pela mediação da professora.

Como em qualquer processo de leitura, é necessário a existência de alguns elementos que contribuem para a atividade de interpretação e construção da linguagem. No caso do mapa não seria diferente, essa representação espacial precisa de determinados elementos que lhe dão sentido, como por exemplo 
a localização, a orientação, a simbologia, a escala (cartográfica e geográfica), a projeção e as coordenadas geográficas (RICHTER, 2010, p. 41).

Assim, a partir dessa afirmação de Richter (2010) compomos um sistema de símbolos e sentidos para ler o mundo pelo mapa. No caso do presente trabalho buscamos compreender o mapa regional, logo as especificidades de leituras são dirigidas para compreender mecanismos de análise de seleção de conteúdos e especificidades quando comparadas com outras regiões. A localização e a legenda são elementos suficientes para ampliar o conhecimento sobre o mundo, mas é preciso que o fator humano do conhecimento esteja presente numa relação dialética entre docentes e discentes.

Neste sentido, Francischett (2014, p.845) entendeu que:

“A concepção da constituição do sujeito em uma dimensão semiótica não ignora a individualidade nem a singularidade, mas atribui-lhe novos significados, quais sejam, a individualidade como um processo socialmente construído".

Essa individualidade socialmente construída é a latência da instância social como evidência teórica e empírica, por isso, não podemos pensar a questão regional a partir da herança de Vidal de La Blache, que sempre esteve a serviço do Estado imperialista francês, mas, conforme Escolar (1996) a Geografia precisa ir além da produção monográfica regional e com isso buscar ampliar as relações que escalarmente não surgem apenas das regiões.

Escolar (1996) nos apresenta uma leitura das categorias geográficas que devem ter suas incorporações simbólicas nos novos significados dos sujeitos que foram social e espacialmente construídos. A leitura do mapa, portanto, deveria partir das necessidades latino-americanas, como nos ajudou pensar Escolar (1996), e não da reprodução das relações estabelecidas pelas categorias oriundas da Europa, com isso essa leitura de mapa não trouxe questões próprias para a Geografia Escolar e faz com que alunas e alunos se percam na motivação do sentido interpretativo e comunicativo dos mapas para entender o próprio país.

Santos (1987) sinaliza a promoção o modelo cívico como um sentido civilizatório, como um modo de vida comum a todos aqueles que pertencem ao mesmo território. O modelo cívico, para Santos (1987) se forma da cultura e do território. Assim, a partir de Vygostky (1990 e 1998), encontramos o modelo cívico como condição para interpretar os mapas regionais, já que as relações do modo de vida e o sentido dessa vida estarão na leitura desses mapas por meio de uma mediação de conceitos e direções para pensar uma especificidade temática. As críticas de Escolar (1996) nos colocam diante dos limites que temos para ir além 
dos conceitos estruturantes de uma Geografia imperialista que domina o sistema para criação de conceitos.

As leituras dos mapas regionais não tratam apenas de limites, já que as relações entre as informações partem do próprio questionamento do sentido em regionalizar. Entendemos que a regionalização para a compreensão geográfica é positiva quando essa não limite as análises e nem hierarquiza as mesmas, ou seja, o trabalho com as regiões possibilita também além da compreensão das divisões administrativas e naturais, elementos clássicos da regionalização do espaço brasileiro, a promoção de novas regiões a partir da Geografia Escolar fundamentando nos sujeitos a capacidade de subtrair regiões existente e pensar até mesmo na possibilidade de outras classificações regionais.

O que desejamos fomentar nesse trabalho é a possibilidade de criação a partir de uma leitura reflexiva dos mapas, tal criação parte de uma definição conceitual e essa ligada a questão da cultura voltada para o modo de vida das pessoas, em outras palavras, o modelo cívico é apresentado como componente informativo daqueles que leem os mapas.

O mapa pertence tanto ao autor (falante/autor) quanto ao interlocutor (leitor), embora o autor seja o proprietário da enunciação, não do ponto de vista da propriedade material, mas do ponto de vista da materialidade sígnica da palavra. O mapa, ao ser apresentado ao aluno (leitor), revela determinadas relações sociais das quais os interlocutores (quem faz quem apresenta) participam, senão ele não tem significado. (FRANCISCHETT, 2014, p. 849).

A participação docente como mediação e sistematizadora de conceitos deve partir da realidade imediata discente, pois essa realidade precisa corporificar a materialidade diária nas representações dos sujeitos. Ler o mapa é uma condição de aprendizado para as questões geográficas, mas não se trata de um processo diretivo de ensino e sim de um movimento dialético para o ensino-aprendizagem dentro de uma composição não apenas de interpretação, mas, sobretudo, de criação.

As regiões geográficas representadas pelos mapas podem sofrer interferências paralisantes para a reflexão quanto aos elementos destacados nos mapas. Cada região brasileira foi construída num dado sentido com especificidades de seus elementos e aplicadas ao mapa a partir de representações variáveis no plano com dimensões próprias de localização e distribuição das informações. Deste modo, Martinelli (2013) coloca as representações numa dimensionalidade interpretativa qualitativa e com isso a dinâmica das informações e comunicações são fundamentadas ora em mapas únicos com muitas informações ou muitos mapas com informações únicas com os quais a/o docente possa mediar a promoção do conceito e da empiria. 
As informações contidas nos mapas e correspondentes às suas respectivas legendas fornecem um sistema de apresentação para a realidade, todavia, essa realidade será compreendida se corresponder aos conceitos que nutrem a compreensão com elementos empíricos que levem ao entendimento da realidade. Assim, é fundamental exercitar com alunas e alunos o movimento de leitura do mapa e suas complexidades. (MARTINELLI, 2013; FRANCISCHETT, 2014).

As representações dinâmicas não estão presentes em todos os mapas, por isso o papel docente é fundamental para a composição do entendimento de símbolos, signos e significados. A intencionalidade do mapa é a condição prévia para iniciar a sua leitura e a sistematização dos conceitos.

A região para ser ensinada a partir dos mapas temáticos elenca uma configuração própria que a distância de outras ou aproxima por similitudes. A região pode englobar as questões naturais e/ou antrópicas nas suas muitas possibilidades. A pergunta fundamental para a iniciar o trabalho é quem delimitou a região? A região delimitada por um órgão ou instituto do Governo Federal ou Estadual ou Municipal? Ou a região foi configurada por um grupo de pesquisadoras e pesquisadores? Enfim, é importante a origem da delimitação (autora/autor ou órgão/instituição) para entender o título do mapa, sua escala, localização e dinâmica.

Diante disso, as exigências pedagógicas para o ensino de Geografia pela Cartografia e seus mapas temáticos regionais passam pela sistematização de conceitos e pela leitura dos símbolos e signos com seus significados no cotidiano.

O ensino de Geografia parte sempre de um currículo e nos últimos anos esse foi sendo centralizado ora não obrigatoriamente como os PCNs (Parâmetros Curriculares Nacionais), todavia as políticas de livros didáticos e os financiamentos para os Estados da federação e para as escolas públicas tornavam os PCNs "obrigatório informalmente". Agora desde 2017 a BNCC (Base Nacional Comum Curricular) é um documento que orienta obrigatoriamente centralizando o conteúdo curricular nacionalmente. As questões apresentadas até o momento serão explicitadas pelas questões cartográficas na Geografia Escolar no próximo ponto. 


\section{3- ENSINO DE GEOGRAFIA PELOS MAPAS TEMÁTICOS REGIONAIS}

O ensino de Geografia é composto por inúmeras questões teóricas e práticas as quais promovem uma condição ímpar para compreender o mundo, já que a ciência geográfica é responsável por ensinar para estudantes do ensino básico questões ligadas a realidade que os mesmos vivem e com isso serem preparados para compreenderem as múltiplas escalas e fatores que infuenciam seus cotidianos. Desta forma, é notório o ensino como responsável por fomentar nos sujeitos o interesse pelo mundo e esse iniciado nas suas relações imediatas da casa, do bairro, da escola, da cidade, do campo, enfim, das suas muitas possibilidades de existência e referência espacial.

A partir da relação Cartografia e Geografia torna-se importante elencar temas e problemas oriundos do ensino de Geografia a partir do ensino da Cartografia, com isso entendemos que a educação geográfica passa pela formação da linguagem cartográfica, conforme exigência institucional listada na Base Nacional Comum Curricular (2017), logo a educação geográfica depende do aprendizado cartográfico para que os e as estudantes tenham uma compreensão ampla do mundo e consigam as ferramentas teóricas para a prática diária na relação direta das representações do vivido e do mundo com suas múltiplas questões.

A Cartografia Escolar não é uma ciência auxiliar da Geografia Escolar, pois a ciência geográfica constitui construção epistemológica a partir da relação da linguagem e das representações do mundo apresentados em escalas diferentes e interrelacionadas; assim, a Cartografia na escola é parte integrante da educação geográfica e impossível de ser fragmentada. Essa condição da Cartografia como componente teórico voltado para a prática geográfica é exigência científica, pedagógica e didática para as práticas docentes no ensino fundamental.

Deste modo, a Cartografia, com suas questões teóricas e práticas, promove o desenvolvimento de competências, habilidades e reflexões que passam pelas urgências do cotidiano e pelas críticas que devem ser estabelecidas socialmente.

Deste modo, a Cartografia desenvolve competências e habilidades voltadas para a leitura e interpretação de mundo. Segundo a BNCC $(2017$, p. 8) a competência é:

“[... ] definida como a mobilização de conhecimentos (conceitos e procedimentos), habilidades (práticas, cognitivas e socioemocionais), atitudes e valores para resolver demandas complexas da vida cotidiana, do pleno exercício da cidadania e do mundo do trabalho (BRASIL, 2017, p. 8)". 
Do ponto de vista geográfico a Cartografia é a base para aprender o mundo a partir de uma leitura sistematizada com uma metodologia definida, assim, a leitura de mapas não é apenas uma construção didática e pedagógica, sim uma edificação de uma forma de compreender o mundo pela ciência. Conforme Barbosa (2020, p. 02):

A cartografia escolar não é apenas parte da disciplina Geografia, pois o aprendizado cartográfico insere os sujeitos numa forma de pensar e organizar o mundo. Essa organização inicia pelo movimento dialético entre imagem, linguagem e vivência espacial. A cartografia escolar fomenta a reflexão dos espaços inseridos na lógica designada pelas legendas e escalas voltadas para os objetivos da informação, localização e precisão espacial.

Diante disso, esse trabalho centra suas questões na formação de alunos e alunas do ensino fundamental por meio do desenvolvimento de uma linguagem visual universalizante, mas não definidora de forma homogeneizadora, para o conhecimento cotidiano nas suas múltiplas relações de imagens, técnicas e tecnologias para compreender os mapas temáticos regionais.

Com as inúmeras interfaces diárias usadas por alunos e alunas seja pelos aparelhos televisos, computadores, celulares ou tablets esses conseguem compreender questões de forma e conteúdo pela relação entre o desenho estrturado pela interface da informática e da comunicação e sua correspondência na vida real; assim, o uso da Internet aparece cada vez mais em nosso cotidiano e essa tecnologia precisa ser usada para que estudantes compreendam o espaço não apenas pela localização, mas, sobretudo, pela relação dinâmica que se efetiva pela exposição aos diversos recursos técnicos e tecnológicos como as fotos aéreas, imagens de satélite, jogos virtuais, imagens e filmagens de drones, sistema GPS de navegação nos celulares e tablets.

Essa interface da tecnologia com o cotidiano escolar é fundamental para a formação de uma solidificação crítica quanto a técnica de observação, mapeamento, descrição e análise pela linguagem cartográfica e geográfica.

O processo de compreensão da realidade pelo ensino da Cartografia implica em fomentar as análises pela correlações, comparaçoes, congruências, continuidades, descontinuidades, agrupamentos, desarranjos, enfim, o mapa, seja impresso ou virtual, é fixado sempre com imagens estáticas do mundo, todavia essa inércia não pode ser considerada a partir de uma lógica euclidiana.

Assim, ultrapassar a Geografia euclidiana significa admitir as elaborações renovadas de espaço geográfico que têm como referência a concepção de espaço relativo, que abrem caminho para reflexão e representação de outras métricas espaciais (inclusive métricas construídas socialmente) como meio de superar a visão 
localizacionista, distributivista e descritivista da Cartografia convencional, suportada rigorosamente pela concepção de espaço absoluto, ou espaço geométrico, algo que está automatizado ou naturalizado. (FONSECA, 2004, p. 43).

Assim, a partir de Fonseca (2004) e Santos (1987 e 2009) buscamos compreender a Cartografia escolar como dinâmica para superar o descritivismo da localização e ensinar que nada é automático na leitura dos mapas e de mundo. A leitura geral e os detalhes do mapa são importantes para que existe uma compreensão ampla dos temas e problemas inseridos no mesmo e associados com o cotidiano dos alunos e alunas do ensino fundamental; assim, os detalhes das representações cartográficas são precisões sobre o espaço na relação direta ou indireta sobre a realidade, com isso cada vez mais precisos os detalhes mais compreende os fenômenos naturais e sociais, bem como suas dinâmicas e sua distribuição fatoral sobre o espaço.

Neste sentido, o trabalho em sala de aula mostra-se necessário, pois a análise do mapa é crucial para que entenda a Geografia como condição das questões espaciais e, desta forma, as alunas e alunos compreendam todos os resultados da pesquisa científica elaborada na sala de aula a partir de temas, problemas, mapas, legendas e objetivos informativos que tragam a eficiência do pensamento científico.

O trabalho educativo pela Geografia passa obrigatoriamente pelo desenvolvimento do pensamento crítico e reflexivo dentro de uma lógica científica e direcionado para que se efetive os processos de ensino-aprendizagem exigidos pela BNCC ao elencar competências e habilidades próprias que resultem numa educação integral e de qualidade. Segundo a BNCC (2017, p. 355) são sete competências específicas de Ciências Humanas para o Ensino Fundamental, assim, todas as competências são possíveis de serem trabalhadas e desenvolvidas pela Cartografia Escolar a partir do ensino de Geografia pelas especificidades e dinâmicas regionais.

Deste modo, as competências das ciências humanas são fundamentais para articular um ensino de Geografia capaz de demonstrar a realidade na sua diversidade, todavia, a BNCC apresenta a competência número 7 da seguinte forma:

7. Utilizar as linguagens cartográfica, gráfica e iconográfica e diferentes gêneros textuais e tecnologias digitais de informação e comunicação no desenvolvimento do raciocínio espaço-temporal relacionado a localização, distância, direção, duração, simultaneidade, sucessão, ritmo e conexão.

Isso signifa que a linguagem cartográfica está reduzida a uma dinâmica euclidiana, como apontou Fonseca (2004), logo essa composição teórica precisa 
constiuir nova forma de organização pedagógica para apresentar a dinâmica didática e científica.

A educação cartográfica estática não permite que o mapa e a relação desse com outras interfaces de informação e comunicação consigam promover dialeticamente o conhecimento exigido pela BNCC e pela própria sociedade, já que a escola é promovedora do conhecimento científico e da formação das futuras gerações pela qualificação e aprimoramento em todos os aspectos do conhecimento e do convívio social.

Nessa direção, a BNCC está organizada com base nos principais conceitos da Geografia contemporânea, diferenciados por níveis de complexidade. Embora o espaço seja o conceito mais amplo e complexo da Geografia, é necessário que os alunos dominem outros conceitos mais operacionais e que expressam aspectos diferentes do espaço geográfico: território, lugar, região, natureza e paisagem. (BNCC, 2017, p. 361).

Assim, a região entra na responsabilidade da Cartografia Escolar não apenas por exigência da BNCC, mas por ser uma categoria significativa para o processo ensinoaprendizagem para permitir que as outras competências da BNCC sejam interrelacionadas e aplicadas, dentre tais competências destacamos as seguintes na relação entre Geografia, Cartografia e Dinâmicas e Especificidades Regionais.

A figura 01 ao analisarmos a mesma sem qualquer legenda não temos informações necessárias para distinguir as 5 cores do mapa e as linhas delimitadoras ou que dividem algo. A figura o1 é o fragmento de uma mapa regional e esse torna-se uma região e podemos muito bem nomear essa região, mas para isso é preciso entender o que aproxima e o que distancia as questões que fundamentam essa região. Assim, esse simples fragmento tem ampla possibilidade pedagógica vygotskyana para promover conceitos e sistemas de pensamentos reflexivos. Observemos: 


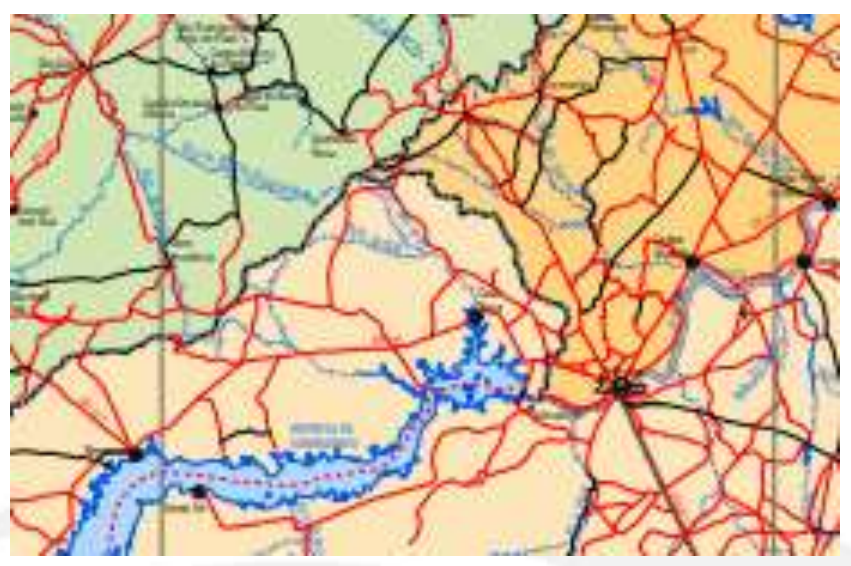

Fig. 01 - Fragmento do mapa da região nordeste. Fonte: IBGE, 2017.

Ao lermos a legenda da figura 01 já sabemos de qual mapa pertence o fragmento, bem como sabemos a autoria do mesmo. Todavia, não se pode conhecer as informações. Assim, é importante ensinar para alunas e alunos que as diferentes cores se referem a diferentes áreas, visto que o espaço representado por essas cores parece bem amplo, mas ainda não se pode afirmar o tamanho, pois não temos nenhuma certeza quanto a escala e localização. Nem mesmo podemos afirmar sobre as linhas pretas, vermelhas e azuis. Esse momento é importante fundamentar para alunas e alunos os conceitos que promovem um mapa e definir sua importância. A partir de Santos (1987) conseguimos olhar para a figura 01 e exercitar o conhecimento prévio ou espontâneo (VYGOSTSKY, 1990) pela promoção de nossa constituição do modo de vida, da cultura e como olhamos objetivamente o mundo. É fundamental o exercício da criatividade para as respostas a partir das questões formuladas pelas/pelos docentes. Tais questões partirão sempre da realidade social, econômica e cultural espacializada.

Santos (1987) edifica a cidadania a partir da responsabilidade com a compreensão da própria liberdade, assim, a partir da figura 01, como exemplo para o processo didáticopedagógico, colocamos questões para a fundamentação da leitura da figura 01, isto é, olhamos para a mesma a partir do sentido que promovemos no mundo. Esse ponto podemos chamar de diagnóstico da compreensão dos sentidos cartográficos para as alunas e alunos, podemos permitir que os mesmos busquem informações em livros ou mesmo na internet para entender as próprias linhas, figuras e delimitações.

Depois de alguns minutos é importante recolher as respostas discentes e verificar o que entenderam desse fragmento de mapa. Esse entendimento será debatido e, posteriormente, será mostrado a legenda completa do mapa: 


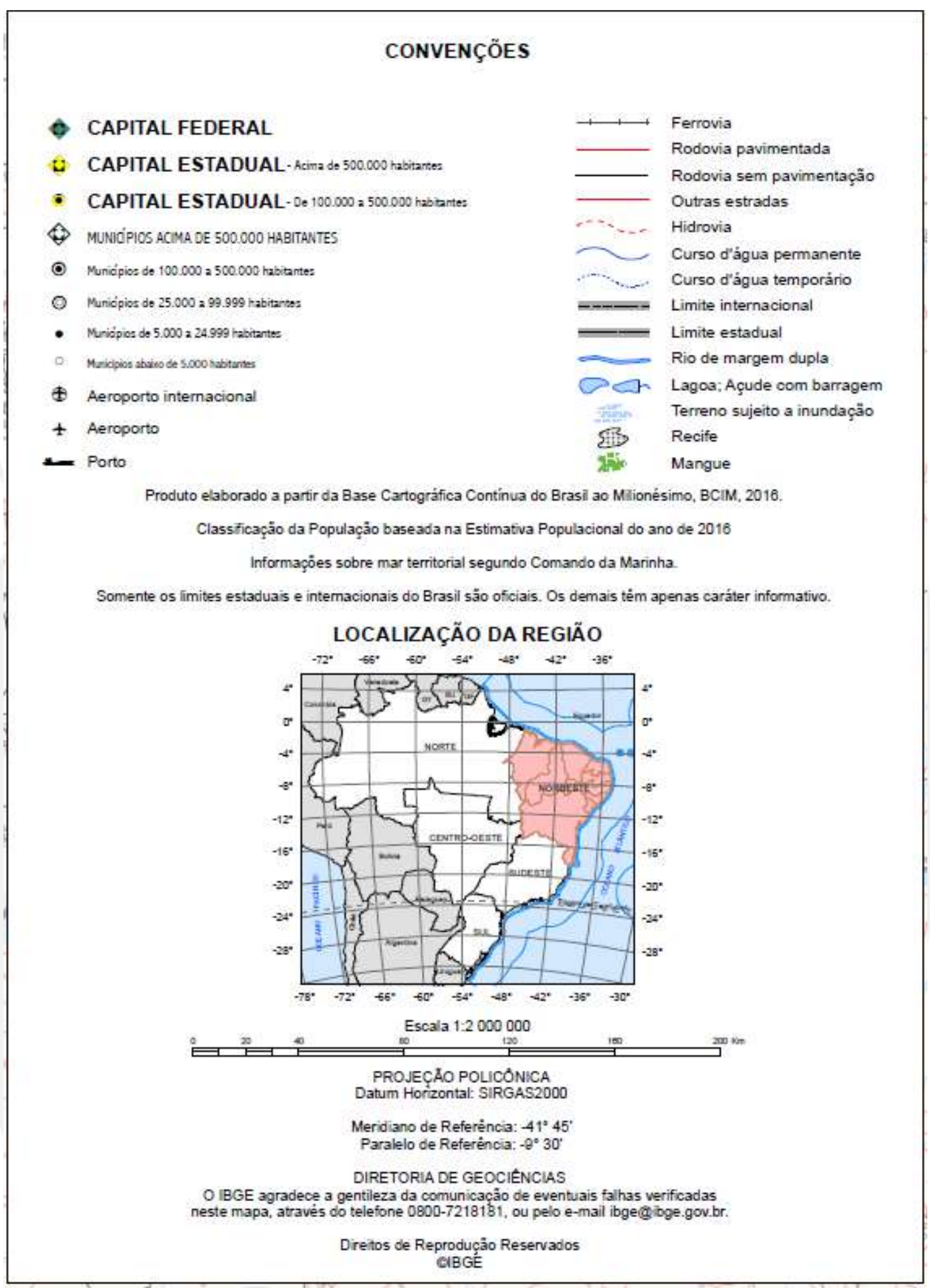

Fig 02 - Legenda completa para entender a figura 01. Fonte: IBGE, 2017.

A partir da figura 02 é possível compreender os elementos da figura 01, mesmo assim, existe uma dificuldade para entender as fronteiras entre os Estados. A delimitação cartográfica da região nordeste em rosa no mapa seleciona visualmente os objetivos dos temas que compõem a região, isso é, as alunas e alunos compreenderão que o destaque para refletir é o que se diferencia pela cor. As outras regiões serão ignoradas, mas se pensarmos 
didaticamente pela ampliação da relação e compreensão da totalidade essas regiões mapeadas sem destaques e sem cores precisam compor as questões geográficas, ou seja, é preciso que elas existam também e construam os argumentos para pensar na região em destaque. A região não existe pela exclusividade e sim pela comparação e definição de seus limites e possibilidades.

A figura 01 evidencia três Estados da federação (Piauí, Pernambuco e Bahia) esses estão representados por suas fronteiras e integrações dessas nas delimitações dos seus Estados. O fragmento do mapa, a figura 01, não tem informações suficientes; assim, somente foi possível anunciar os Estados pela leitura do mapa original que representa toda a região nordeste3. Assim, é importante junto com discentes buscarem o mapa original com todas as informações e destacar como o mesmo tem especificidades que não podem ser compreendidas nem por fragmentos e nem pela simples leitura da legenda.

O movimento de compreensão da totalidade do mapa é importante para a vivência das alunas e alunos no entendimento das regiões como fundamentos para a totalidade do país. Martinelli (2013) volta suas questões para a dinâmica do mapa temático e com isso consolida uma representação do movimento que é ao mesmo tempo informação e comunicação para fundamentar o conhecimento geográfico. Todavia, o próprio Martinelli (2013) ao tecer críticas aos mapas temáticos estáticos também constitui a solução para os mesmos buscando o fluxo e o sentido das informações.

O mapa do IBGE (2017), que aqui representamos na figura 01 e 02, não tem um sentido de fluxo ou mobilidade, pois as rodovias, estradas, ferrovias e hidrovias existem enquanto realidade, mas não como movimento. É necessário construir o movimento nos mapas, mas como isso não foi possível nesses exemplos é papel da organização curricular e das atividades escolares fundamentarem essa dinâmica. Precisamos, enquanto docentes, promovermos o movimento e o sentido desse na compreensão dos fluxos e das informações dadas que não prestam à ampliação do conhecimento. Após o diagnóstico e a leitura da legenda com a compreensão do mapa original é possível representarmos os fluxos e as direções da dinâmica empreendida regionalmente e, depois, os mecanismos de aproximação ou de distanciamento dessas regiões pelos fluxos ou de pessoas ou de mercadorias.

É preciso imaginar o uso da legenda no cotidiano na sala de aula e como a mesma precisa de complementações as quais serão dadas pelas necessidades das alunas e dos alunos

\footnotetext{
3 O mapa original está disponível no site https://geoftp.ibge.gov.br/cartas e mapas/mapas regionais/politico/2017/nordeste politico200ok 2017.pdf. Recomendamos estudar o mesmo para que compreenda melhor a dinâmica.
} 
ao mesmo tempo em que providenciam novas leituras das regiões. O caminho metodológico para compreender as regiões pela Cartografia Escolar passa pela dinâmica geográfica que precisa articular o conhecimento socialmente produzido com as exigências do Estado e seus limites. Devemos, em nosso papel de tutores, assumir uma postura de trazer uma leitura dinâmica quanto aos elementos que se apresentam estáticos. Somente com essa leitura será possível aproximar o conteúdo trabalhado com a realidade vivida, estimulando, dessa forma, a criticidade das alunas e dos alunos, permitindo que o processo ensino-aprendizagem seja feito de forma a transcender o objetivo da educação euclidiana, apresentando e construindo junto com as turmas as relações regionais ali estabelecidas de uma forma que faça sentido no âmbito individual dos discentes.

[...]cada professor, dependendo do perfil de sua sala, dos conhecimentos e informações que possui, deve elaborar as pr6prias questões que servirão de elementos provocadores da aprendizagem dos conhecimentos geográficos. Por isso, e importante que o próprio profissional faça constantes exercícios de leitura de mapas, para que possa verificar inclusive, que conhecimentos devem ser estudados a fim de estabelecer raciocínios explicativos para a organização e configuração de determinadas paisagens. (KATUTA, 2002, p. 179)

Conforme visto no fragmento, ainda em 2002, Katuta já denotava a importância de se recorrer a essa abordagem personalizada de ensino. Há de se refletir os motivos que levam uma discussão que já perdura duas décadas ainda não ter sido devida e amplamente implementada e se apresentar como carente na rede ensino brasileira. Pereira e Menezes (2016), confirmam a realidade deficitária desse tipo de ensino, evidenciando que em grande parte isso ocorre por falhas no processo formativo dos próprios docentes, que carecem do ensino das metodologias que envolvam a reflexão a criticidade do conteúdo, ficando reféns do material didático que costuma ser apresentado de forma estática. Assim, inferimos que o problema não se encontra apenas no uso de metodologias não adequadas ao ensino, como também na ausência da devida capacitação dos profissionais responsáveis por ele.

\section{CONSIDERAÇÕES FINAIS}

Diante do exposto podemos perceber que o ensino de geografia, principalmente no tocante as questões do ensino regional por meio da cartografia, está fortemente embasado em metodologias tradicionais e defasadas, que não consideram a realidade e as especificidades da sala de aula a qual é aplicado.

Cremos ser necessária uma mudança radical no posicionamento dos professores quanto a forma de trazer o conteúdo aos seus estudantes. Quando consideramos o uso da 
cartografia e sua leitura em sala de aula, os docentes não podem deixar de fazer uma interpretação dinâmica em relação ao material apresentado, havendo a necessidade de se adaptarem conforme as demandas da turma.

Entretanto, esse papel de dinamização não deve ficar a encargo apenas dos docentes. É preciso que lutemos por uma postura mais concisa do governo e das instituições de ensino, para que elas passem a abraçar essa abordagem mais humanizada do processo ensinoaprendizagem. Ressaltamos que há necessidade de capacitações dos profissionais já formados, assim como da revisão das ementas curriculares de diversos cursos para que eles formem docentes críticos e autônomos.

O ensino fortemente técnico que impregna as escolas brasileiras está longe de ser superado, mas isso não deve nos abater de permanecer no movimento pela melhora do sistema como um todo. A vivência dos estudantes deve ser valorizada, pois é a dialética da relação professor-aluno que traz à tona a verdadeira face do ato de educar e a partir do momento que excluímos as experiências e especificidades dos alunos e alunas desse processo, passamos a ter uma relação professor-material didático, o que nos faz apenas perpetuar o sistema tecnicista que aliena e escraviza a sociedade.

\section{REFERÊNCIAS}

BRASIL. Ministério da Educação. Secretaria de Educação Básica. Base Nacional Comum Curricular. Brasília: MEC/Consed/Undime, 2017.

BARBOSA, T. Ensino da Cartografia Escolar pelo Materialismo Histórico e Dialético: Abordagem Anticolonial. Uberlândia: IG-UFU, 2020.

FONSECA, F. P. A inflexibilidade do espaço, uma questão para a Geografia: análises das discussões sobre o papel da Cartografia. São Paulo: Programa de PósGraduação em Geografia Física - USP, 2004. Disponível em: https://www.teses.usp.br/teses/disponiveis/8/8135/tde-09082010-130954/pt-br.php.

FRANCISCHETT, M. N. Construindo elos metodológicos na linguagem cartográfica. Revista Brasileira de Cartografia, v. 66, n. 4, 11, 2014. Disponível em: http://www.seer.ufu.br/index.php/revistabrasileiracartografia/article/view/44686/23700

. Acesso em 21/06/2020

GOMES, P C. da C. O conceito de região e sua discussão. In: CASTRO, Iná E.; GOMES, P. C.; CORRÊA, R. L. Geografia: conceitos e temas. Rio de Janeiro, Bertrand Brasil, 1995, p. $49-76$ 
JOLY, F. A cartografia. Campinas: Papirus, 1990.

KATUTA, Â. M. A leitura de mapas no ensino de Geografia. Nuances (Presidente Prudente), Presidente Prudente, v. 8, p. 167-182, 2002.

MARTINelli, M. Os Mapas da Geografia e Cartografia a Temática. São Paulo: Contexto, 2013.

PEREIRA, B. M.; DE MENEZES, P. K. Os desafios com a cartografia no processo de ensinoaprendizagem de geografia. Revista Brasileira de Cartografia, v. 69, n. 9, 8 ago. 2018. RICHTER, D. Raciocínio geográfico e mapas mentais: a leitura espacial do cotidiano por alunos do Ensino Médio. Presidente Prudente: UNESP, 2010.

RIQUE DA SILVA, L. Do senso-comum à Geografia Científica. São Paulo: Contexto, 2004.

SANTOS, M. A Natureza do Espaço: Técnica e Tempo, Razão e Emoção - São Paulo: USP, 2009.

SANTOS, M. O espaço do cidadão. São Paulo: Nobel, 1987.

VYGOTSKY, L. S. A formação social da mente. São Paulo: Martins Fontes, 1998. VYGOTSKY, L. S. Pensamento e linguagem. São Paulo: Martins Fontes, 1990. 